There was no TLR at 6 month and only $2(3.3 \%)$ at 1 year. TVR was $1(1.6 \%)$ at 6 month with no further cases at 1 year.

Conclusions In one of the largest clinical experiences to date, the Sideguard stent can be used to treat complex bifurcation lesions in a straight forward manner, with excellent short and long term clinical outcomes.

\section{LACK OF GENDER DIFFERENCE AND IMPROVED IN-HOSPITAL MORTALITY RATES IN PATIENTS WITH CARDIOGENIC SHOCK FOLLOWING PRIMARY PERCUTANEOUS CORONARY INTERVENTION: A UK TERTIARY CARDIAC CENTRE REGISTRY STUDY}

doi:10.1136/heartjnl-2012-301877b.32

${ }^{1} \mathrm{~V}$ Kunadian, ${ }^{*} \mathrm{M}$ Veerasamy, ${ }^{2} \mathrm{~S}$ Jamieson, ${ }^{2} \mathrm{~A}$ Zaman. ${ }^{1}$ Newcastle University, UK; ${ }^{2}$ Freeman Hospital, UK

Background Despite substantial recent improvement in mortality from cardiovascular disease, due primarily to success of primary and secondary prevention strategies, it remains the leading cause of death in the developed world. Among those patients hospitalised with acute myocardial infarction (AMI), cardiogenic shock (CS) is the foremost cause of death complicating up to $10 \%$ of admissions. Introduction of early revascularisation strategies and mechanical ventricular support have seen short-term mortality due to CS fall from $70 \%$ to $80 \%$ in the 1970 s to around $50 \%-60 \%$ in the 1990 s. Previous studies suggest that women experience more CS than men $(11.6 \%$ vs $8.3 \%)$ in the setting of ST elevation MI. Whether primary percutaneous coronary intervention (PPCI) for AMI has resulted in further reduction in in-hospital mortality and whether there are gender differences in outcomes due to CS is not known.

Aims The aim of this study is to determine the rate of in-hospital mortality following primary PCI in the setting of CS and examine the gender differences in the incidence of CS and the rate of in-hospital mortality.

Methods Data were collected prospectively among all patients presenting with AMI to a large UK tertiary cardiac centre and undergoing PPCI between April 2008 and October 2011.

Results In total 2866 patients (male: 2023 [70.6\%] vs female: 843 [29.4\%]) underwent PPCI. In total, 141/2866 (4.9\%) had percutaneous coronary procedures (balloon angioplasty only or stenting) in the setting of cardiogenic shock. There were 81/2023 [4\%] male patients and $60 / 843$ [7.1\%]) female patients with CS undergoing PPCI. There were no significant differences in the baseline characteristics between male and female patients except female patients were older than men (male: mean age 64.1 years vs female

Abstract 032 Table 1

\begin{tabular}{|c|c|c|c|c|}
\hline Variables & $\begin{array}{l}\text { Total } \\
n=141 / 2866 \\
(4.9 \%)\end{array}$ & $\begin{array}{l}\text { Male } \\
n=81 / 2023 \\
(4 \%)\end{array}$ & $\begin{array}{l}\text { Female } \\
n=60 / 843 \\
(7.1 \%)\end{array}$ & p Value \\
\hline Mean age-years (SD) & $66.6(13.7)$ & $64.2(12.3)$ & $69.9(15.0)$ & 0.004 \\
\hline Hypertension (\%) & $60(42.5)$ & $32(39.5)$ & $28(46.6)$ & 0.434 \\
\hline Diabetes mellitus (\%) & $20(14.1)$ & $10(12.3)$ & $10(16.6)$ & 0.730 \\
\hline Hypercholesterolaemia (\%) & $42(29.7)$ & $22(27.1)$ & $20(33.3)$ & 0.465 \\
\hline Previous angina (\%) & $33(23.4)$ & $17(20.9)$ & $16(26.6)$ & 0.577 \\
\hline $\begin{array}{l}\text { Previous myocardial } \\
\text { infarction }(\%)\end{array}$ & $22(15.65)$ & $12(14.8)$ & $10(16.6)$ & 0.777 \\
\hline $\begin{array}{l}\text { Previous percutaneous } \\
\text { coronary intervention (\%) }\end{array}$ & 7 (4.9) & $3(3.7)$ & $4(6.6)$ & 0.436 \\
\hline $\begin{array}{l}\text { Previous coronary artery } \\
\text { bypass graft }(\%)\end{array}$ & $2(1.4)$ & $1(1.2)$ & $1(1.6)$ & 0.832 \\
\hline In-hospital mortality (\%) & $50(35.4)$ & $29(35.8)$ & $21(35)$ & 0.730 \\
\hline
\end{tabular}

69.9 years, $\mathrm{p}=0.004)$. The overall unadjusted in-hospital mortality rate was $35.4 \%$ with no difference in the genders (male: $35.8 \%$ vs female: $35 \%, p=0.730)$.

Conclusion The present analysis demonstrates that in the PPCI era, there is reduction in the incidence of cardiogenic shock with reduced unadjusted in-hospital mortality rates following primary PCI. The unadjusted in-hospital mortality rates did not differ between the genders despite the fact that there were more women that had presented with cardiogenic shock.

\section{OUT-OF-HOURS MORTALITY IN THE CURRENT PRIMARY PERCUTANEOUS CORONARY INTERVENTION ERA}

doi:10.1136/heartjnl-2012-301877b.33

A Noman,* J Ahmed, A Bagnall, I Spyridopoulos, M Egred. Freeman Hospital, UK

Background There is conflicting evidence to whether the outcomes of primary percutaneous coronary Intervention (PPCI) for STsegment elevation myocardial infarction (STEMI) are as favourable out of hours as during routine working hours.

Aim To assess the impact of the time of PPCI on the mortality in STEMI. Main outcome measures: In-hospital and long-term allcause mortality.

Method Retrospective analysis of prospectively collected data on 2571 consecutive STEMI patients treated with PPCI between March 2008 and June 2011 at a regional tertiary centre. Of these, 1036 patients (40.3\%) underwent PPCI at weekdays between 08:00 and 18:00 (routine-hours group) and 1535 patients (59.7\%) underwent PPCI at weekdays between 18:00 and 08:00 or at weekends (out-ofhours group).

Results Compared to the routine-hours group, the out-of-hours group had a lower mean age $(62.5 \pm 13.1$ vs $64.1 \pm 13.7$ years, $\mathrm{p}=0.001$ ), a lower proportion of patients with previous history of angina $(18.9 \%$ vs $23.6 \%, p=0.005)$ and a longer call-to-hospital time. The two groups were otherwise similar in all other clinical and procedural characteristics. The overall cohort in-hospital mortality rate was $4.5 \% ; 4.2 \%$ in the routine-hours group and $4.6 \%$ in the outof-hours group (OR; $1.05,95 \%$ CI 0.72 to $1.54, \mathrm{p}=0.794$ ). During a mean follow-up period of 560 days, a total of 295 patients died $(11.5 \%)$. Of these, 126 were in the routine-hours group $(12.2 \%)$ and 169 in the out-of-hours group (11.0\%). In the multiple Cox's proportional hazards model, there was no difference in mortality between the two groups (adjusted HR; 1.09, 95\% CI 0.82 to 1.46; $\mathrm{p}=0.565)$. Similarly, no difference in mortality was seen in patients, who underwent PPCI at late-night time (22:00-06:00).

Conclusions PPCI outside routine working hours is safe with no difference in outcome of in-hospital and long-term mortality in comparison to PPCI during routine-working hours.

\section{THE EFFECT OF THROMBUS ASPIRATION DURING PRIMARY PERCUTANEOUS CORONARY INTERVENTION ON IN- HOSPITAL MORTALITY AND THROMBOLYSIS IN MYOCARDIAL INFARCTION FLOW GRADE}

doi:10.1136/heartjnl-2012-301877b.34

A Noman, ${ }^{*}$ M Egred, I Spyridopoulos, A Bagnall, J Ahmed. Freeman Hospital, UK

Background Thrombus aspiration (TA) has been shown to improve Myocardial Blush Grade and ST-segment resolution in patients undergoing primary percutaneous coronary intervention (PPCI) for ST-segment elevation myocardial infarction (STEMI). However, the effect of thrombus aspiration on Thrombolysis In Myocardial Infarction (TIMI) flow grade and the survival of these patients remains uncertain. 
Aim To assess the effect of thrombus aspiration on TIMI flow grade and in-hospital mortality in PPCI-treated STEMI patients Main outcome measures: Post-PPCI TIMI flow grade and in-hospital mortality.

Method Analysis of prospectively collected data of all STEMI patients undergoing primary PCI between March 2008 and June 2011 at a regional tertiary centre.

Results A total of 2567 patients (mean age $63.2 \pm 13.4$ years, $70.3 \%$ male) were included in this analysis. TA was performed in 1095 patients $(42.7 \%)$ (the thrombectomy group), whereas 1472 patients (57.3\%) underwent PPCI without TA (the non-thrombectomy group). Post PPCI TIMI flow grade 3 was achieved in $94.6 \%$ in the thrombectomy group compared to $88.7 \%$ in the non-thrombectomy group (adjusted OR; 2.0, 95\% CI 1.41 to $2.83, \mathrm{p}=0.0001$ ). Overall inhospital mortality was $4.5 \%(n=115)$. In a logistic regression model adjusted for many confounders, the use of thrombus aspiration was associated with a significant reduction in in-hospital mortality ( $2.7 \%$ vs $5.8 \%$, adjusted OR; $0.514,95 \%$ CI 0.29 to $0.93, p=0.027)$. Other independent predictors of in-hospital mortality in this model were advanced age, total ischaemic time, admission systolic blood pressure and heart rate, pre-procedural TIMI flow, admission haemoglobin and creatinine and multi-vessel coronary artery disease.

Conclusions In this large observational study of "real world" and unselected STEMI patients, manual thrombus aspiration during PPCI was associated with a significant reduction in in-hospital mortality and an increase in the rate of post-procedural TIMI flow grade 3 . These findings further confirm the benefits of thrombus aspiration in these patients.

\section{THROMBECTOMY AND PLATELET GLYCOPROTEIN IIB/IIIA BLOCKADE FOR STENT THROMBOSIS}

doi:10.1136/heartjnl-2012-301877b.35

M M Akhtar, * D A Jones, S Gallagher, R Weerackody, E Sammut, K S Rathod, A Jain, C Knight, A Mathur, A Wragg. Barts \& The Royal London Hospital, UK

Background Both mechanical thrombectomy and glycoprotein (GP) IIb/IIIa antagonists have been shown to improve clinical outcomes following primary PCI for ST segment elevation myocardial infarction. There is limited data describing the use of these technologies in the setting of stent thrombosis. We aimed to assess the combined approach of mechanical thrombectomy with adjunctive glycoprotein (GP) IIb/IIIa antagonists in patients presenting with acute stent thrombosis.

\section{Abstract 035 Table 1}

\begin{tabular}{lclll}
\hline & $\begin{array}{l}\text { No GPIlb/IIla or } \\
\text { thrombectomy } \\
\mathbf{N}=\mathbf{2 1}\end{array}$ & $\begin{array}{l}\text { No GPIlb/IIla or } \\
\text { thrombectomy } \\
\mathbf{N = 9 2}\end{array}$ & $\begin{array}{l}\text { No GPIIb/IIla or } \\
\text { thrombectomy } \\
\mathbf{N = 8 8}\end{array}$ & p Value \\
\hline Age & $55.25 \pm 30.0$ & $64.05 \pm 11.7$ & $62.72 \pm 12.6$ & 0.060 \\
Gender (female) & $7(35.0 \%)$ & $29(31.5 \%)$ & $22(25.0 \%)$ & 0.517 \\
Previous MI & $10(50.0 \%)$ & $54(58.7 \%)$ & $60(68.2 \%)$ & 0.215 \\
Previous CABG & $1(5.0 \%)$ & $7(7.6 \%)$ & $5(5.7 \%)$ & 0.837 \\
Hypercholesterolaemia & $7(35.0 \%)$ & $53(57.6 \%)$ & $50(56.8 \%)$ & 0.165 \\
Hypertension & $11(55.0 \%)$ & $53(57.6 \%)$ & $51(58.0 \%)$ & 0.971 \\
DM & $4(20.0 \%)$ & $25(27.2 \%)$ & $24(27.3 \%)$ & 0.786 \\
EGFR <60 & $4(20.0 \%)$ & $19(20.7 \%)$ & $21(23.9 \%)$ & 0.851 \\
MV disease & $6(30.0 \%)$ & $43(46.7 \%)$ & $36(40.9 \%)$ & 0.359 \\
Card Shock & $2(10.0 \%)$ & $6(6.5 \%)$ & $6(6.8 \%)$ & 0.855 \\
EF $<40$ & $11(55.0 \%)$ & $34(37.0 \%)$ & $23(26.1 \%)$ & 0.035 \\
Troponin (mean) & $1.65 \pm 2.98$ & $1.05 \pm 2.15$ & $2.44 \pm 4.43$ & 0.210 \\
Procedural Success & $17(85.0 \%)$ & $85(92.4 \%)$ & $85(96.6 \%)$ & 0.139 \\
\hline
\end{tabular}

Methods This was an observational cohort study of 3040 patients who underwent PPCI from 2003 to 2011. The primary outcome was major adverse cardiac events (all cause mortality, myocardial infarction, target vessel revascularisation and stroke). Follow-up was for a median of 3.0 years (IOR 1.2-4.6 years). Patients were split into 3 groups; those who underwent PCI using mechanical thrombectomy and GP IIb/IIIa inhibitors, those receiving either GPIIb/IIIa inhibitor or mechanical thrombectomy and those receiving neither.

Results 201 patients (6.6\%) of all STEMI patients presented with stent thrombosis (ST). Overall, GPIIb/IIIa inhibitors were used in $176(87.6 \%)$ patients. Mechanical thrombectomy was used in 94 (46.7\%) patients. 88 (44\%) patients received both GPIIb/IIA inhibitors and thrombectomy, $92(46 \%)$ received either GPIIb/IIIa inhibitor or thrombectomy and $21(10 \%)$ received neither therapy. Baseline characteristics of these 3 groups are shown in Abstract 035 table 1. Patients receiving both therapies tended to have more successful procedures and have better post-procedural left ventricular function. Kaplan-Meier estimates of long-term major adverse cardiac events showed the lowest rates of events for those patients receiving both therapies, followed by those receiving a single therapy, with the highest rates of MACE in those receiving neither therapy $(p<0.0001)$ (Abstract 035 figure 1). All individual component of MACE were lower in those receiving both therapies. Age-adjusted Cox analysis showed a decrease in the hazard of death for those receiving both therapies compared to those receiving neither (HR 0.17 (95\% CIs 0.06 to 0.54 ) and this was maintained with multiple adjustment (HR 0.11 (95\% CIs 0.02 to 0.85 )

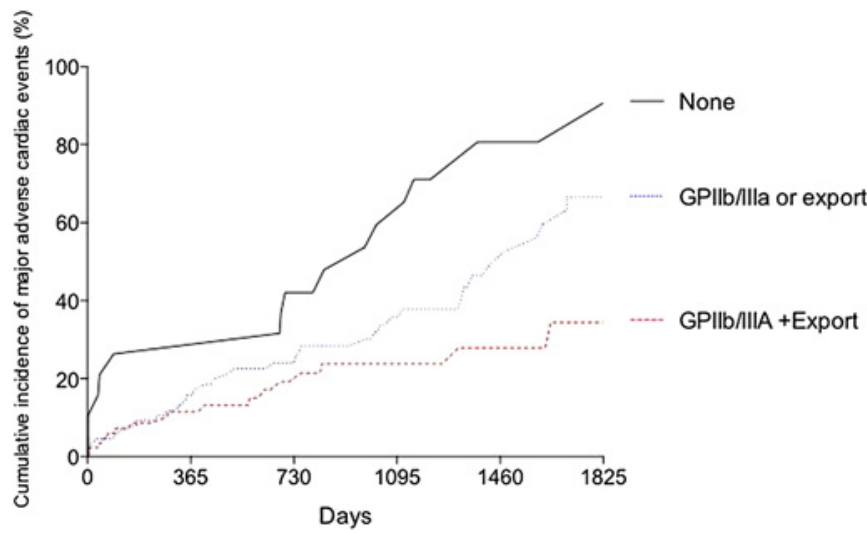

\section{Abstract 035 Figure 1}

Conclusion Prognosis after stent thrombosis is poor with high longterm event rates. Using a combined approach of mechanical thrombectomy with adjunctive GP IIb/IIIa blockade lead to effective primary PCI with improved long-term outcomes.

\section{NO DIFFERENCE IN LONG-TERM MAJOR ADVERSE CARDIAC EVENT RATES BETWEEN PACLITAXEL-ELUTING AND SIROLIMUS-ELUTING STENTS}

doi:10.1136/heartinl-2012-301877b.36

H A Abu-Own,* D A Jones, S M Gallagher, K S Rathod, A K Jain, C Knight, A Mathur, A Wragg. London Chest Hospital, UK

Background Previous studies have demonstrated similar outcomes over the short to mid term in patients treated with paclitaxeleluting stents (PESs) or sirolimus-eluting stents (SESs). However there is limited "real-world" data investigating long term outcomes. This study compared outcomes at 5 years following revascularisation in these two patient groups. 